\title{
MORTALITY AMENABLE TO HEALTH CARE IN EUROPEAN UNION COUNTRIES AND ITS LIMITATIONS
}

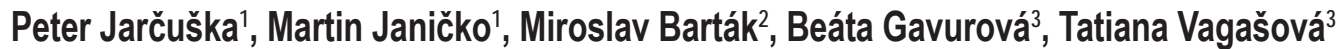 \\ ${ }^{1} 1$ st Department of Internal Medicine, University Hospital and Faculty of Medicine, Pavol Jozef Šafárik University in Košice, Košice, Slovak \\ Republic \\ ${ }^{2}$ Department of Addictology, First Faculty of Medicine, Charles University and General University Hospital in Prague, Prague, Czech Republic \\ ${ }^{3}$ Faculty of Economics, Technical University of Košice, Košice, Slovak Republic
}

\section{SUMMARY}

Aim: The concept of amenable mortality is intended to assess health care system performance. It is defined as "premature deaths that should not occur in the presence of timely and effective health care". The purpose of paper is to analyse differences in amenable mortality across European Union countries and to determine the associations between amenable mortality and life expectancy at birth.

Methods: This is a cross-country and time trend analysis. Data on deaths by cause, and five-year age groups were obtained from the World Health Organization database for the 20 European Union countries, throughout the period from 2002 to 2013 . The rates of amenable mortality were expressed by the age-standardised death rates per 100,000 inhabitants. We applied the method of direct standardisation using the European Standard Population.

Results: Throughout the explored period, the statistically significant variations of the age-standardised death rates in a relation to the European Union average fluctuated from 78.7 per 100,000 inhabitants (95\% Cl 72.4-84.9) in France to 374.3 per 100,000 inhabitants (95\% Cl 350.8-397.7) in Latvia. The leading causes of amenable mortality were ischaemic heart disease, cerebrovascular diseases, and colorectal cancer that accounted for, respectively, $42.2 \%, 19.5 \%$, and $11.3 \%$ of overall amenable mortality. As expected, statistically significant strong negative relationship $\left(R^{2}=0.95\right.$; $\rho=-0.98$ ) between amenable mortality and life expectancy at birth was proved by linear regression. The concept has several limitations relating to the selection of causes of death and setting age threshold over time, not consideration actually available health care resources in each country, as well as differences in the prevalence of diseases among countries.

Conclusions: We found an explicit divide in amenable mortality rates between more developed countries of Western, Northern and Southern Europe, and less developed countries of Central and Eastern Europe. Increasing of amenable mortality may suggest deterioration in health care system performance.

Key words: amenable mortality, health care system performance, life expectancy, European Union countries

Address for correspondence: B. Gavurová, Faculty of Economics, Technical University of Košice, Němcovej 32, Košice, Slovak Republic. E-mail: beata.gavurova@tuke.sk

https://doi.org/10.21101/cejph.a4956

\section{INTRODUCTION}

There has been growing interest in the determination of health systems' performance between countries and in their contribution to health of population. It is partially determined by various health outcomes indicators, commonly considering length of life. General mortality data and consequently life expectancy are accessible for the longest time period within the health status data. They are generally considered the most reliable health outcomes indicators for international comparison across countries. However, general mortality data represents a rough health status indicator that is itself insufficient for the assessment of medical care benefits. As for premature deaths, not all reflect the accessibility and effectiveness of health care system. For decades, researchers have been looking for the ways how to measure the proportion of the health care system to health status of population. Although, there is no indicator that would comprehensively reflect the performance of health care system, nevertheless, the suitable measurement seems to be the concept of avoidable mortality.

The concept of avoidable mortality, as an indicator for the quality of healthcare services, was firstly developed by Rutstein et al. (1), who defined deaths from selected disease groups that are considered either treatable, or preventable through the medical services. Further, they divided the avoidable mortality into the two subsets of amenable mortality with the timely and effective health care services (e.g. diabetes mellitus treated with insulin), and preventable mortality by interventions programs (e.g. lung cancer prevented by smoking elimination). Their list of causes of death included about 80 diseases. Many researches have tried to renew the list over time adjusting to the new medical and technological advances (2-9). Gay et al. (10) estimated amenable mortality for 31 OECD countries and assessed this indicator by 
comparing the two widely used lists of causes of death: Nolte and McKee from 2008 (8) and Tobias and Yeh from 2009 (9). The results of the lists were similar. The highest amenable mortality rates were identified in the Eastern European countries and Mexico, on the contrary to the Japan, France, Italy, and Sweden with the lowest values. The recent study "Amenable mortality in the European Union: toward better indicators for the effectiveness of health systems” (AMIEHS) from 2011 (11) introduces a new way of selecting diseases into the lists of causes of death that are amenable to health care. Based on previous studies, the Office for National Statistics in England (12) defines amenable and preventable mortality as follows. „A death is amenable if, in the light of medical knowledge and technology at the time of death, all or most deaths from that cause (subject to age limits if appropriate) could be avoided through good quality health care. A death is preventable if, in the light of understanding of the determinants of health at time of death, all or most deaths from that cause (subject to age limits if appropriate) could be avoided by public health interventions in the broadest sense.“

Most studies applied the list of causes of death by Nolte and McKee (8) or by Tobias (9) for amenable mortality analyses (13-16). The latest study on amenable mortality, AMIEHS project (11), provides trends of standardised mortality rates in European countries according to the recent list of causes of deaths over the period 2001-2009 by the electronic atlas of amenable mortality (17). In this research, Eastern European countries had higher rates of causes of death amenable to health care than Northern and Western European countries. To date, there have been no studies conducted to update the evolution of amenable mortality up to the latest available year 2013, in addition, the relationships between amenable mortality and others health indicators are missing.

The main objectives of this paper are:

- to evaluate differences in amenable mortality across European Union (EU) countries between 2002 and 2013,

- to reveal the relative position of countries with relation to the European Union average for the leading causes of death in amenable mortality,

- to determine the associations between amenable mortality and life expectancy at birth.

\section{MATERIALS AND METHODS}

\section{Data}

Our main source of mortality data was the World Health Organization (WHO) database, where the causes of death are coded using the ICD-10 classification, by the five-year age groups. The data in the required structure were available for $20 \mathrm{EU}$ countries for the period 2002-2013, while others EU countries did not meet the requirements of this analysis due to data incompleteness. However, data for Denmark, Estonia, Latvia, and Romania were available up to 2012; for France up to 2011; and for Slovenia only up to 2010. We selected causes of death that were proposed by the AMIEHS research group (Table 1), with age limit 75 years. Statistical Database of the United Nations Economic Commission for Europe was the main source for data on mid-year population at the age groups in every year. Data on life expectancy at birth was downloaded from OECD database.
Table 1. List of causes of death considered amenable to health care, AMIEHS list

\begin{tabular}{|l|c|}
\hline $\begin{array}{l}\text { Cause of death considered amenable } \\
\text { to health care }\end{array}$ & ICD - 10th revision \\
\hline HIV & B20-24 \\
\hline Colorectal cancer & C18-21 \\
\hline Breast cancer & C50 \\
\hline Cervical cancer & C53 \\
\hline Testis cancer & C62 \\
\hline Hodgkin's disease & C81 \\
\hline Leukaemia & C91-95 \\
\hline Ischemic heart disease & $120-25$ \\
\hline Rheumatic and other valvular heart disease & $100-09$ \\
\hline Hypertensive heart disease & $110-13$ \\
\hline Heart failure & $150-51$ \\
\hline Cerebrovascular disease & $160-69$ \\
\hline Peptic ulcer disease & $\mathrm{K} 25-26$ \\
\hline Nephritis and nephrosis & $\mathrm{N} 17-19$ \\
\hline Perinatal deaths, all causes (excl. stillbirths) & P00-96 \\
\hline Congenital malformations & Q20-24 \\
\hline
\end{tabular}

Adapted from Plug et al. 2011 (11).

\section{Analyses}

We analysed levels and trends of amenable mortality by estimating age-standardised death rate (ASDR) per 100,000 inhabitants. The method of direct standardisation to the European standard population (18) was used with the aim to remove any effect from variations in the age structure across countries or over time. The age-standardised death rates were calculated by:

$$
A S D R=\frac{\sum_{x} m_{x} \cdot P_{x}^{*}}{\sum_{x} P_{x}^{*}}
$$

Where: $x$ - age/sex group 0-4, 5-9,..., 70-74; $m_{x}$ - observed mortality rate (deaths per 100,000 persons) in sex/age group; $P_{x}^{*}$ - European Standard Population in age group $\mathrm{x}$.

Forest plot was used to reveal the national variance of ASDRs (with 95\% confidence intervals) compared to the EU average (18). A difference is statistically significance if confidence intervals (CI) around rate non-overlap a value of EU average (19). We further calculated relative ASDR differences between countries for categories of diseases in relation to the EU average that were illustrated by radar plot. Finally, the association between amenable mortality rates and life expectancy were expressed by correlation index and linear regression as proposed in the study (10).

\section{RESULTS}

\section{Differences in Amenable Mortality across EU Countries}

Figure 1 shows the current level of amenable mortality rates in EU countries in 2013 or latest available year. EU average of amenable mortality accounted for 160 deaths per 100,000 inhabitants. The ASDRs ranged from 68 per 100,000 in France to 318 
per 100,000 in Latvia. Generally, the experienced countries of Central and Eastern European Union recorded the higher values of amenable mortality than EU average, while more developed Western, Northern and Southern European Union countries, showed a lower level of amenable mortality.

Figure 2 shows the national distribution of the European Union countries' amenable mortality rates (with 95\% CI) in relation to the European Union average throughout the period 2002-2013. A statistically significant variation was proved, with a range from 78.7 per 100,000 (95\% CI 72.4-84.9) in France to 374.3 per 100,000 (95\% CI 350.8-397.7) in Latvia. For countries Latvia, Romania, Lithuania, Hungary, Estonia, Slovakia, Croatia, and Poland, ASDRs were statistically significantly higher than the European Union average. For Czech Republic, ASDRs did not differ statistically significantly from the European Union average, whereas 95\% CI of ASDRs exceeded the EU average. Conversely, ASDRs were statistically significantly lower than the European Union average in Malta, Slovenia, Finland, United Kingdom, Germany, Denmark, Sweden, Luxembourg, Netherlands, Spain,

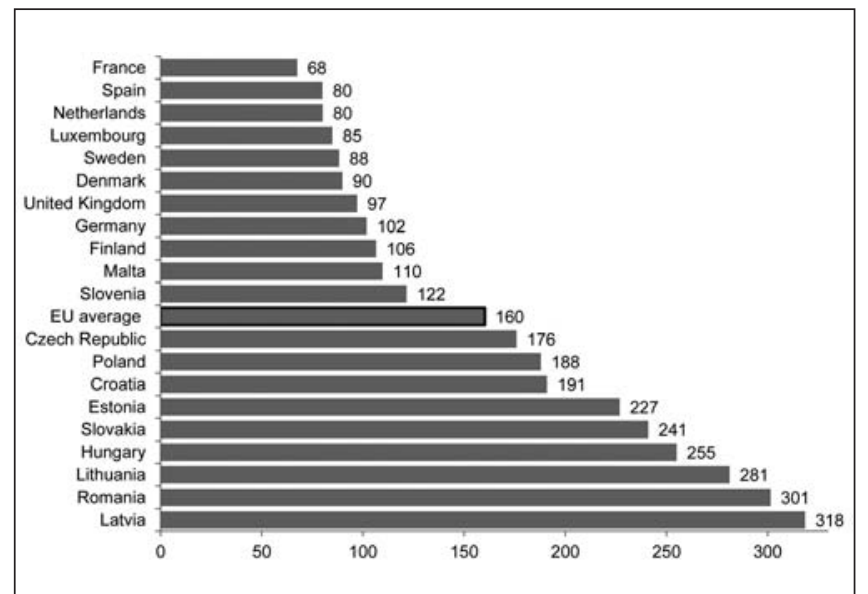

Fig. 1. Amenable mortality rates per 100,000 inhabitants, 2013 or last available year.

2012 data for Denmark, Estonia, Latvia, Romania; 2011 data for France; 2010 data for Slovenia.

Source: own calculations from http://www.who.int/healthinfo/statistics/mortality_rawdata/en/

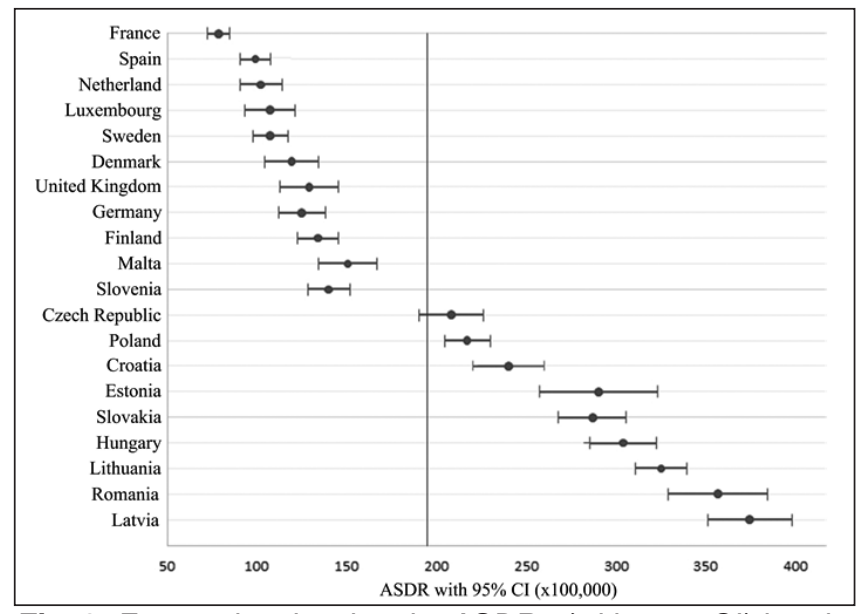

Fig. 2. Forest plot showing the ASDRs (with 95\% Cl) in relation to the EU average (vertical line) for the years 2002-2013. ASDR - age-standardised death rate; $\mathrm{Cl}$ - confidence interval.

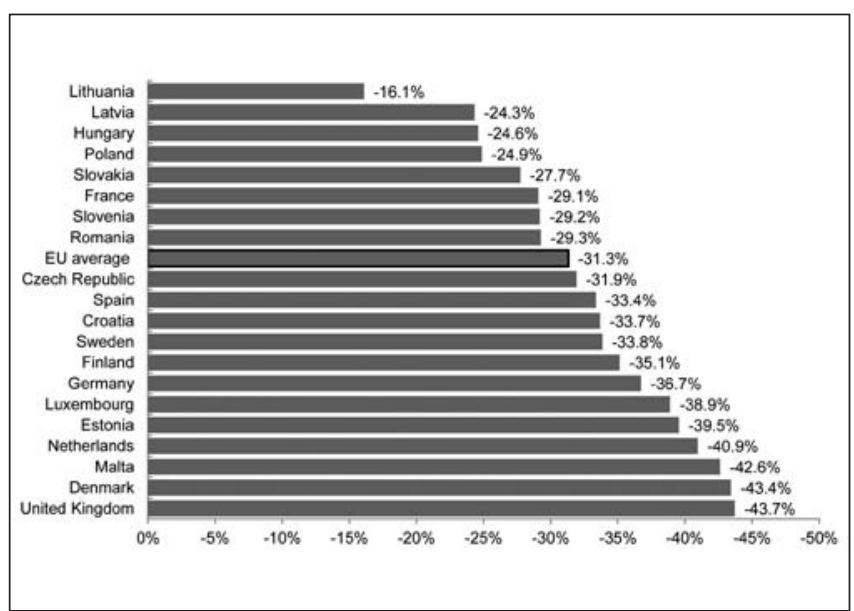

Fig. 3. Change in amenable mortality, 2002 to 2013.

Source: own calculations from http://www.who.int/healthinfo/statistics/mortality_rawdata/en/

and France. These results prove that there is a statistically significant geographical variance in amenable mortality rates, except Czech Republic, from the European Union average also in the long-term perspective.

During the study period from 2002 to 2013, amenable mortality declined in all the experienced European Union countries (Fig. 3). EU average drop was at a value of 31.3\%. Other annual declines ranged from $16.1 \%$ in Lithuania to $43.7 \%$ in United Kingdom. As it is seen, Lithuania significantly lags behind the Baltic States, namely Estonia (-39.5\%), Slovenia (-29.2\%), and Latvia (-24.3\%). Considering countries of the Visegrad region, Czech Republic achieved the highest decrease of amenable mortality $(-31.9 \%)$, higher than EU average $(-31.3 \%)$. On the contrary, declines of amenable mortality in Slovakia $(-27.7 \%)$, Poland (-24.9\%), Hungary (-24.6\%) were below the EU average. Annual declines larger than $40 \%$ were recognised in Netherlands, Malta, Denmark and United Kingdom.

\section{Relative Position of Countries with Relation to the EU Average for the Leading Causes of Death in Amenable Mortality}

We examined the contributions of diseases to overall amenable mortality in experienced EU countries in 2013, or latest available year (Table 2). The leading cause of amenable mortality was ischaemic heart disease that accounted for $42.2 \%$ of overall amenable mortality. Share of cerebrovascular diseases in total amenable mortality was $19.5 \%$ and colorectal cancer explained $11.3 \%$. Other causes of death contributed less than $8 \%$.

Figure 4 shows relative positions of countries by comparison to the EU average for the first three most common disease categories and total amenable causes. Countries with good results of overall amenable mortality usually have mortality rates by disease category below the EU average. Commonly, there are some exceptions, for instance, Slovenia has a relatively high rate of amenable mortality for colorectal cancer. On the other hand, countries reflecting worse values of overall amenable mortality usually have mortality rates by disease category above the EU average, except Poland for ischaemic heart disease, Czech Republic for cerebrovascular disease, Lithuania due to colorectal cancer, and Estonia for colorectal cancer and for cerebrovascular disease. 
Table 2. Contribution to overall amenable mortality, 2013 or last available year, AMIEHS list

\begin{tabular}{|c|c|c|c|c|c|c|c|c|c|c|c|c|c|c|c|c|}
\hline Cour & 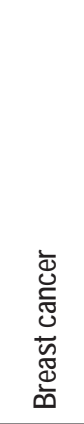 & 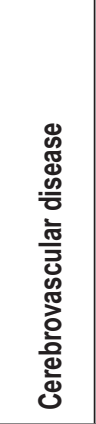 & 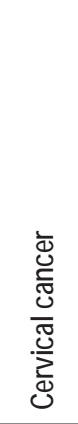 & 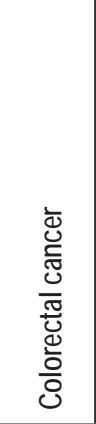 & 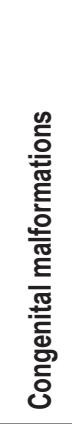 & 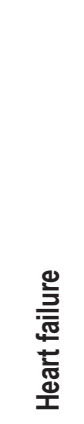 & 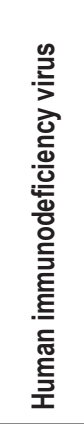 & 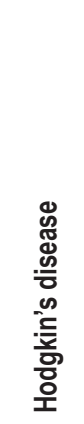 & 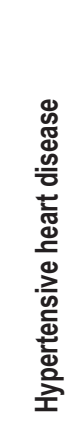 & 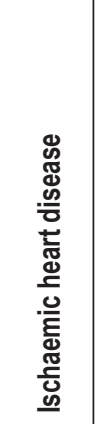 & 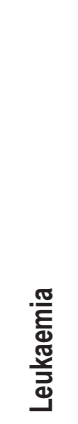 & 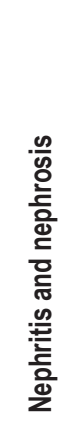 & 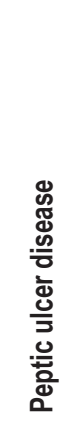 & 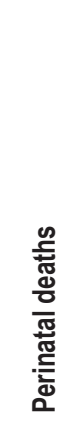 & 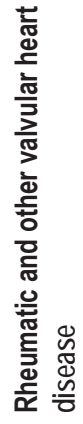 & 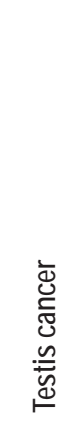 \\
\hline Croatia & $\%$ & $.9 \%$ & $1.1 \%$ & $12.7 \%$ & $0.3 \%$ & $3.5 \%$ & $0.1 \%$ & $0.2 \%$ & $4.9 \%$ & $40.5 \%$ & $.9 \%$ & $0.9 \%$ & $1.0 \%$ & $.4 \%$ & $0.5 \%$ & $.2 \%$ \\
\hline Czech & $5.6 \%$ & $.9 \%$ & $6 \%$ & $11.8 \%$ & $0.3 \%$ & $6.8 \%$ & $0.0 \%$ & $0.2 \%$ & $4.9 \%$ & $48.0 \%$ & 120 & $1.2 \%$ & $1.1 \%$ & $0.8 \%$ & $0.6 \%$ & $0.1 \%$ \\
\hline Denmark & $1 \%$ & $.0 \%$ & $5 \%$ & $.2 \%$ & $0.4 \%$ & $5.3 \%$ & $0.5 \%$ & $3 \%$ & $2 \%$ & $.5 \%$ & $1.2 \%$ & $\%$ & $\%$ & $0 \%$ & $0.2 \%$ & $2 \%$ \\
\hline Estonia & $.1 \%$ & $2.1 \%$ & $2.0 \%$ & $6.8 \%$ & $0.4 \%$ & $3.0 \%$ & $1.9 \%$ & $0.2 \%$ & $22.4 \%$ & $41.7 \%$ & $1.0 \%$ & $0.3 \%$ & $0.9 \%$ & $0.7 \%$ & $0.4 \%$ & $0.1 \%$ \\
\hline Finland & $9.1 \%$ & $18.3 \%$ & $0.5 \%$ & $10.6 \%$ & $0.6 \%$ & $3.5 \%$ & $0.1 \%$ & $0.2 \%$ & $4.7 \%$ & $48.6 \%$ & 0.8 & $0.4 \%$ & $1.5 \%$ & $0.7 \%$ & $0.1 \%$ & $0.2 \%$ \\
\hline France & $0 \%$ & $6 \%$ & $5 \%$ & $.1 \%$ & $0.8 \%$ & $7.2 \%$ & $1.0 \%$ & $0.4 \%$ & $3.3 \%$ & $25.7 \%$ & 1 & $2.0 \%$ & $0.4 \%$ & $2.6 \%$ & $1.0 \%$ & $0.2 \%$ \\
\hline Germany & $.5 \%$ & $4.0 \%$ & $1.3 \%$ & $13.4 \%$ & $0.5 \%$ & $6.8 \%$ & $0.5 \%$ & $0.2 \%$ & $5.2 \%$ & $38.9 \%$ & $1.2^{\circ}$ & $3.0 \%$ & $0.8 \%$ & $1.8 \%$ & $0.7 \%$ & $0.2 \%$ \\
\hline Hungary & $6 \%$ & $7.8 \%$ & $1.4 \%$ & $12.4 \%$ & $0.4 \%$ & $3.6 \%$ & $0.0 \%$ & $0.1 \%$ & $8.5 \%$ & $45.2 \%$ & 0.9 & $0.4 \%$ & $1.6 \%$ & $1.3 \%$ & $0.4 \%$ & $0.1 \%$ \\
\hline Latvi & $4.4 \%$ & $23.9 \%$ & $1.6 \%$ & $6.3 \%$ & 0 & $1.8 \%$ & $1.5 \%$ & $0.2 \%$ & $6.2 \%$ & $50.5 \%$ & & $0.1 \%$ & $0.9 \%$ & $1.2 \%$ & $.5 \%$ & $\%$ \\
\hline Lithuania & $4.6 \%$ & $22.6 \%$ & $1.8 \%$ & $6.0 \%$ & $0.4 \%$ & $0.3 \%$ & $0.4 \%$ & $0.1 \%$ & $3.5 \%$ & $56.2 \%$ & 0.7 & $0.3 \%$ & $1.7 \%$ & $0.5 \%$ & $0.8 \%$ & $0.1 \%$ \\
\hline Luxemb & $.1 \%$ & $.7 \%$ & $2.2 \%$ & $17.3 \%$ & $0.8 \%$ & $5.6 \%$ & $0.5 \%$ & $0.8 \%$ & $2.9 \%$ & $38.5 \%$ & 0.9 & $2.3 \%$ & $0.3 \%$ & $1.7 \%$ & $0.3 \%$ & $0.0 \%$ \\
\hline Malta & 17 & 170 & $0.5 \%$ & 4 & 0. & 4.5 & 0 & $0.3 \%$ & 2. & $49.2 \%$ & $0.2 \%$ & $2.0 \%$ & $0.2 \%$ & $2.9 \%$ & $0.0 \%$ & $\%$ \\
\hline Netherlands & $5.1 \%$ & $17.2 \%$ & $1.3 \%$ & $20.8 \%$ & $0.7 \%$ & $8.7 \%$ & $0.2 \%$ & $0.4 \%$ & $2.9 \%$ & $26.1 \%$ & $1.5 \%$ & $1.7 \%$ & $0.5 \%$ & $2.6 \%$ & $0.3 \%$ & $0.2 \%$ \\
\hline Poland & $6.3 \%$ & $19.9 \%$ & $2.0 \%$ & $10.5 \%$ & $0.5 \%$ & $22.6 \%$ & $0.2 \%$ & $0.2 \%$ & $2.7 \%$ & $29.5 \%$ & 1. & $1.3 \%$ & $1.1 \%$ & $1.2 \%$ & $0.6 \%$ & $0.2 \%$ \\
\hline Romania & $4.0 \%$ & $28.7 \%$ & $2.4 \%$ & $6.4 \%$ & $0.4 \%$ & $2.6 \%$ & $0.3 \%$ & $0.2 \%$ & $14.9 \%$ & $35.1 \%$ & 0.6 & $2.3 \%$ & $0.4 \%$ & $1.1 \%$ & $0.4 \%$ & $0.1 \%$ \\
\hline Slovakia & $5.9 \%$ & $18.1 \%$ & $1.8 \%$ & $11.4 \%$ & $0.4 \%$ & $7.3 \%$ & $0.0 \%$ & $0.3 \%$ & $3.2 \%$ & $47.0 \%$ & 1.0 & $1.3 \%$ & $1.0 \%$ & $1.0 \%$ & $0.3 \%$ & $0.2 \%$ \\
\hline Slovenia & $9.6 \%$ & $22.2 \%$ & $1.3 \%$ & $18.1 \%$ & $0.3 \%$ & $3.8 \%$ & $0.0 \%$ & $0.2 \%$ & $4.2 \%$ & $33.6 \%$ & $1.6 \%$ & $1.3 \%$ & $0.8 \%$ & $1.8 \%$ & $1.0 \%$ & $0.1 \%$ \\
\hline Spain & $.8 \%$ & $15.2 \%$ & $1.3 \%$ & $20.6 \%$ & $0.6 \%$ & $7.5 \%$ & $2.0 \%$ & $0.4 \%$ & $3.3 \%$ & $30.7 \%$ & 12 & $2.7 \%$ & $0.4 \%$ & $2.1 \%$ & $1.2 \%$ & $0.1 \%$ \\
\hline Sweden & $.6 \%$ & $15.1 \%$ & $1.3 \%$ & $15.3 \%$ & $0.5 \%$ & $6.5 \%$ & $0.2 \%$ & $0.2 \%$ & $2.9 \%$ & $41.8 \%$ & $1.3 \%$ & $1.1 \%$ & $1.4 \%$ & $1.6 \%$ & $0.3 \%$ & $0.2 \%$ \\
\hline United King. & $11.6 \%$ & $14.9 \%$ & $1.2 \%$ & $13.5 \%$ & $0.7 \%$ & $2.8 \%$ & $0.4 \%$ & $0.3 \%$ & $2.7 \%$ & $45.6 \%$ & 1.1 & $0.9 \%$ & $1.4 \%$ & $2.3 \%$ & $0.5 \%$ & $0.1 \%$ \\
\hline EU-20 & $4 \%$ & $5 \%$ & $6 \%$ & $3 \%$ & $4 \%$ & $1 \%$ & $0.5 \%$ & $0.2 \%$ & $7 \%$ & $42.2 \%$ & 0. & $1.2 \%$ & $1.0 \%$ & $1.3 \%$ & $0.5 \%$ & $\%$ \\
\hline
\end{tabular}

\section{Association of Amenable Mortality with Life Expectancy}

We examined the association between amenable mortality and life expectancy at birth across countries. As might be expected, amenable mortality is negatively correlated with life expectancy at birth, while amenable mortality is included in overall mortality. However, amenable mortality can differ across countries with similar life expectancies. Based on our findings, the determination index $\mathrm{R}^{2}$ indicates that $95.22 \%$ of dependency of our data is explained by negative linear regression (Fig. 5).

We found a very strong negative correlation between amenable mortality and life expectancy $(\rho=-0.98)$. The lowest life expectancy is assigned to Latvia (74.1) and also amenable mortality has the highest value of EU countries (318.5/100,000). On the contrary, the longest life is expected to be in Spain (83.2), similarly, amenable mortality rate reflects the second lowest level among EU countries $(80 / 100,000)$. Some countries have the same value of life expectancy: Latvia and Lithuania (74.1), Denmark and Slovenia (80.4), Finland and United Kingdom (81.1), however Lithuania, Denmark and United Kingdom gained better results of amenable mortality.

\section{DISCUSSION}

Amenable mortality has been developed as a measurement of population health status which deeply relates to the quality of health care. We decided to use AMIEHS list of causes of death amenable to health-care because it is the last modification according to the latest conditions.

All the 20 European Union countries exhibited declines in amenable mortality, what suggests their performance improvements but their pace varied. Although, the age standardised death rate of amenable mortality is the lowest in France $(68 / 100,000)$, suggesting a good quality of health care in amenable conditions, the percent drop of amenable mortality in France (-29.1\%) does not achieve either the value of European Union average decline. Our results are consistent with the study by Nolte and McKee (13), who used their own list of amenable diseases from 2008.

On the contrary, Latvia and Lithuania had one of the highest rates of amenable mortality in 2013 (318/100,000; 281/100,000), indicating poor health care system performance, and they also 


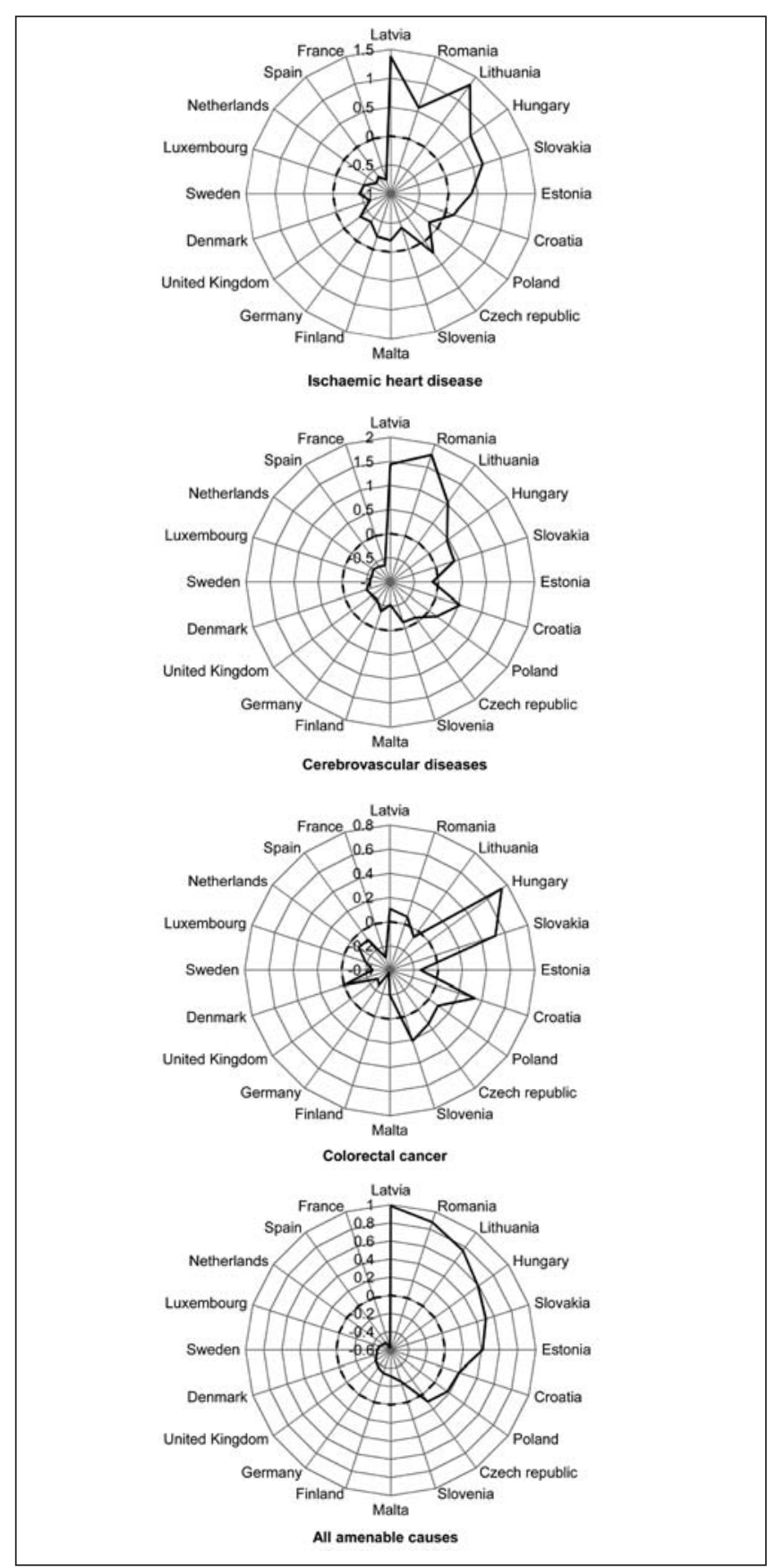

Fig. 4. Relative positions of countries in relation to the EU average, 2013 or last available year.

experienced the smallest improvements in rates $(-24.3 \% ;-16.1 \%)$ between 2002 and 2013. Countries of Visegrad region had different patterns: Hungary, Slovakia and Poland showed above-average amenable mortality and experienced low improvements, while Czech Republic had lowest amenable mortality across these countries and nevertheless achieved the highest progress. Similarly, more than average decline was found in the Czech Republic during the period from 1980 to 1997 (20).

We found an explicit divide in amenable mortality rates between the more developed countries among the western, northern and southern European Union members, and the less developed countries among the central and eastern European Union members in the long term, also at a current level. However, Croatia and Estonia made a considerable progress in achieving the better

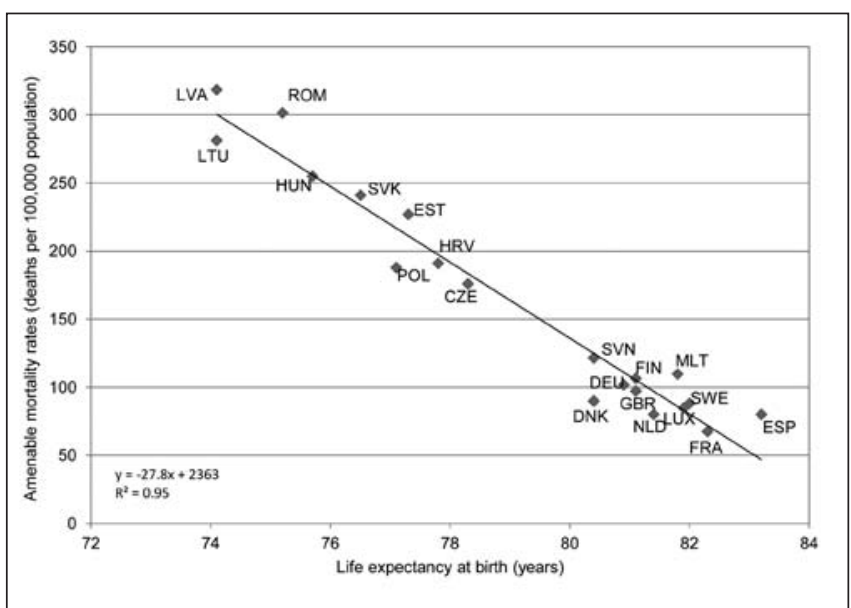

Fig. 5. Life expectancy and amenable mortality in EU countries, 2013 or last available year.

Czech Republic (CZE), Denmark (DNK), Estonia (EST), Finland (FIN), France (FRA), Netherlands (NLD), Croatia (HRV), Lithuania (LTU), Latvia (LVA), Luxembourg (LUX), Hungary (HUN), Malta (MLT), Germany (DEU), Poland (POL), Romania (ROM), Slovakia (SVK), Slovenia (SVN), Spain (ESP), Sweden (SWE), United Kingdom (GBR). Source: own calculations from http://www.who.int/healthinfo/statistics/mortality_rawdata/en/

values of amenable mortality. Our results are consistent with the study by Newey and Nolte (6) who demonstrated a clear east-west divide in amenable mortality.

The differences between Eastern and Western European countries have been documented for poverty (percentage of the population who at-risk of poverty: $17 \%$ in the East and $14 \%$ in the West), and education (percentage of the population with at least lower secondary education: 21\% in the East and 32\% in the West) (21). As for medical procedures, Eastern countries showed an average of 40 MRI exams per million inhabitants in 2013 compared to 50 in Western countries, in addition, the East dispose with the lower number of hospital beds, cardiac procedures, and ambulatory surgery (22).

Further, we revealed statistically significant geographical variance in amenable mortality rates for all countries, except Czech Republic, from the European Union average. In accordance with the study by Treurniet et al. (20), only deaths from leukaemia were statistically non-significant from the average in the Czech Republic.

Our results shows that ischaemic heart disease, cerebrovascular diseases, and colorectal cancer are the leading causes of amenable mortality and explain almost third of total amenable mortality. A possible interpretation of this finding could relate to the high prevalence of mentioned diseases in the EU (23) and disposable scope for increasing the effectiveness of treatment. With regard to the colorectal cancer, Slovenia's worse amenable mortality than other west countries may reflects below average CT scanners in the country (12.6 per million population). Conversely, larger CT scanners in Estonia (17.4 per million population) and Lithuania (23.8 per million population) may contribute to the better rates of colorectal cancer than others east countries (22).

Eastern European countries characterised by higher overall mortality, cardiovascular and cerebrovascular mortality point out the unhealthy lifestyle of their population as well as the low access of cardiovascular and cerebrovascular interventional diagnostics and treatment (24). It would be desirable to develop in these countries national cardiovascular program. Similarly, mortality from color- 
ectal cancer relates to nutritional habits (excessive consumption of fatty foods) as well as a genetic predisposition, especially in the countries of Visegrad region and Slovenia. In many of these countries it is expected to decrease mortality from colorectal cancer after starting screening for colorectal cancer in the population over 50 years, which is financed from public health insurance.

We found a high negative correlation between amenable mortality and life expectancy at birth coincides with Gay et al. (10). Lithuania, Denmark and United Kingdom gained better results of amenable mortality than countries with the same values of life expectancy. Our results indicate success in medical care of diseases considered amenable to health care in these three countries. To rank countries according to amenable mortality indicators is accompanied by the fact that health status of population depends on many others factors, such as socioeconomic factors, lifestyle practises, environmental factors, etc. (25). Therefore, we should be very cautious when interpreting implications of medical interventions on population health considering mentioned limitations in international comparisons.

While amenable mortality seems to be an innovative indicator for measuring the effectiveness of medical services, it has number of limitations (26). There is an absence of international agreement on the uniform selection of causes of death in the cross-country comparison due to the several researched teams interesting in this. It should be kept in mind, that the list of causes of death should be modified over times, since technological innovations of medical treatment at the primary and secondary level have been increasing. Similarly, age limit for premature deaths should vary over time considering age threshold after that medical intervention is not so effective due to the presence of multiple comorbidities. There is the question, if the age limit should not be varied between males and females or between low and high-income countries $(7,27)$. This concept does not take into account that different countries do not have the same health care resources needed for effective treatment, for instance, new technologies or sufficient number of professionals. The lack of resources can lead to the increase of disease prevalence that is not adjusted in the amenable mortality indicator. In spite of these limitations, amenable mortality indicator provides valuable information about the potentials and weaknesses of health care system performance.

\section{CONCLUSIONS}

Our analysis can be used to inform health policy decision makers of each country about the level of unnecessary deaths in the European Union countries, about the leading causes of death amenable to health care, finally, about the relation between life expectancy and amenable mortality. It is necessary to conduct analyses with relation to the regional levels and socioeconomic status of population, in order to introduce specific interventions. Up to now, there are some studies that assessed the regional differences in amenable mortality, e.g. for Italy (28), for Spain (29), for Hungary (30), etc. This seems to be the subject of our further analyses in the field of amenable mortality studies.

\section{Acknowledgement}

This work was supported by the VEGA Project No. 1/0945/17 Economic research on quantification of marketing processes aimed at improving value for patient, multidimensional analyses of the marketing mix of healthcare facilities and quantification of their importance in the process of establishment of the system to measure the quality and efficiency in healthcare of the Slovak Republic.

\section{Conflict of Interests}

None declared

\section{REFERENCES}

1. Rutstein DD, Berenberg W, Chalmers TC, Child CG 3rd, Fishman AP, Perrin EB. Measuring the quality of medical care. N Engl J Med. 1976;294(11):582-8.

2. Charlton JR, Hartley RM, Silver R, Holland WW. Geographical variation in mortality from conditions amenable to medical intervention in England and Wales. Lancet. 1983;1(8326 Pt 1):691-6.

3. Mackenbach JP, Bouvier-Colle MH, Jougla E. "Avoidable" mortality and health services: a review of aggregate data studies. J Epidemiol Community Health. 1990;44(2):106-11.

4. Westerling R, Smedby B. The European Community 'avoidable death indicators' in Sweden 1974-1985. Int J Epidemiol. 1992;21(3):502-10.

5. Holland WW. European Community atlas of avoidable death. 2nd ed. Vol. 2. Oxford: Oxford University Press; 1993.

6. Newey C, Nolte E, McKee M, Mossialos E. Avoidable mortality in the enlarged European Union. Paris: Institut des Sciences de la Santé; 2004.

7. Nolte E, McKee M. Does health care save lives?: Avoidable mortality revisited. London: The Nuffield Trust; 2004.

8. Nolte E, McKee M. Measuring the health of nations: updating an earlier analysis. Health Aff (Millwood). 2008;27(1):58-71.

9. Tobias M, Yeh LC. How much does health care contribute to health gain and to health inequality? Trends in amenable mortality in New Zealand 1981-2004. Aust N Z J Public Health. 2009;33(1):70-8.

10. Gay JG, Paris V, Devaux M, de Looper M. Mortality amenable to health care in 31 OECD countries: estimates and methodological issues. OECD health working papers, no. 55. Paris: OECD Publishing; 2011.

11. Plug I, Hoffmann R, Mackenbach J, editors. AMIEHS: Avoidable mortality in the European Union: towards better indicators for the effectiveness of health systems [Internet]. 2011 [cited 2015 Dec 12]. Available from: http://amiehs.lshtm.ac.uk/.

12. Office for National Statistics. Definitions of avoidable mortality [Internet]. London: ONS; 2011 [cited 2015 Nov 15]. Available from: http://www. networks.nhs.uk/nhs-networks/east-of-england-respiratory-programme/ news/ons-consultation-on-avoidable-mortality-closes-12-april.

13. Nolte E, McKee M. In amenable mortality-deaths avoidable through health care-progress in the US lags that of three European countries. Health Aff (Millwood). 2012;31(9):2114-22.

14. Wheller L, Baker A, Griffiths C, Rooney C. Tends in avoidable mortality in England and Wales, 1993-2005. Health Stat Q. 2007;(34):6-25.

15. Gavurová B, Vagašová T. The significance of amenable mortality quantification for financing the health system in Slovakia. Procedia Econ Finance. 2015;32:77-86.

16. Goldberger N, Haklai Z. Mortality rates in Israel from causes amenable to health care, regional and international comparison. Isr J Health Policy Res. 2012;1:41. doi: 10.1186/2045-4015-1-41.

17. AMIEHS. Atlas of amenable mortality [Internet]. 2011 [cited 2015 Dec 12]. Available from: https://survey.erasmusmc.nl/amiehs/atlas.html.

18. Curtin LR, Klein RJ. Direct standardization (age-adjusted death rates) [Internet]. Hyattsville: Centers for Disease Control and Prevention; 1995 [cited 2015 Nov 10]. Available from: http://www.cdc.gov/nchs/data/statnt/ statnt06rv.pdf.

19. Washington State Department of Health. Guidelines for using confidence intervals for public health assessment [Internet]. Tumwater: Washington State Department of Health; 2012 [cited 2015 Nov 24]. Available from: https://www.doh.wa.gov/Portals/1/Documents/1500/ConfIntGuide.pdf.

20. Treurniet HF, Boshuizen HC, Harteloh PP. Avoidable mortality in Europe (1980-1997): a comparison of trends. J Epidemiol Community Health. 2004;58(4):290-5.

21. Eurostat database. Population by educational attainment level, sex and age (\%) [Internet]. [cited 2015 Nov 24]. Available from: http://appsso. eurostat.ec.europa.eu/nui/show.do?dataset=edat_lfs_9903\&lang=en. 
22. OECD. Health at a glance: Europe 2014 [Internet]. OECD Publishing; 2014 [cited 2015 Dec 13]. Available from: http://www.oecd-ilibrary.org/ social-issues-migration-health/health-at-a-glance-europe-2014 health glance_eur-2014-en.

23. Nichols M, Townsend N, Scarborough P, Rayner M. Cardiovascular disease in Europe 2014: epidemiological update. Eur Heart J. 2014;35(42):2950-9.

24. Gavurová B, Vagašová T. Regional differences of standardised mortality rates for ischemic heart diseases in the Slovak Republic for the period 1996-2013 in the context of income inequality. Health Econ Rev. 2016;6:21. doi:10.1186/s13561-016-0099-1.

25. Jougla E. Indicators of "premature" and "avoidable" mortality. Paris: Haut Conseil de la santé publique; 2013.

26. Gavurová B, Gróf M. Relevance of outcomes implementation of specific economic and social analyses of mortality for modification of avoidable mortality concepts. J Appl Econ Sci. 2016;11(1):65-77.

27. Tobias M. Avoidable mortality in old age. In: WHO Technical Meeting on Ageing and Health; 2010 Jun 2-4; Geneva [Internet]. 2010 [cited 2016 Feb 15]. Available from: http://www.who.int/healthinfo/05 avoidable_mort_Tobias.pdf.
28. Fantini MP, Lenzi J, Franchino G, Raineri C, Burgio A, Frova L, at al. Amenable mortality as a performance indicator of Italian health-care services. BMC Health Serv Res. 2012;12:310. doi: 10.1186/1472-696312-310.

29. Nolasco A, Quesada JA, Moncho J, Melchor I, Pereyra-Zamora P, Tamayo-Fonseca N, et al. Trends in socioeconomic inequalities in amenable mortality in urban areas of Spanish cities, 1996-2007. BMC Public Health. 2014;14:299. doi: 10.1186/1471-2458-14-299.

30. Nagy C, Juhász A, Beale L, Páldy A. Mortality amenable to health care and its relation to socio-economic status in Hungary, 2004-08. Eur J Public Health. 2012;22(5):620-4.

Received October 17, 2016 Accepted in revised form December 19, 2017 